\title{
"Penetrating injury of right foot with Harpoon in a fisherman: A case report"
}

\author{
${ }^{1}$ Omar Khursheed, ${ }^{2}$ Ansarul Haq, ${ }^{3}$ Refut Arah, ${ }^{4}$ Azher Maqbool Khan, \\ ${ }^{5}$ Nazeefa, Shazia Altaf
}

\begin{abstract}
Penetrating injuries caused by fishing equipments like hooks involving hands, face and eyes are common and reported by various authors. Injuries involving foot are rarely reported. We report a 17 years old fisherman with penetrating injury involving the right foot caused by a fishing harpoon. We describe the early removal of the harpoon using "Push Through And Cut Off" technique to prevent the mechanical and infective complications associated with these hooked instruments.
\end{abstract}

\section{Introduction:}

Fishing is a sport enjoyed by millions of people throughout the world and involves all age groups ${ }^{5}$. But for some it is a profession.Penetrating injuries involving the extremities and eyes is seen in both groups ${ }^{3,5,6}$. More is written about eye injuries, perhaps because of the potentially devastating consequences of such an injury, although even an orthopaedic injury that is considered trivial and simple can cause severe incapacitating damage if treated incorrectly ${ }^{5}$. Potential complications of these injuries caused by harpoons are injuries to nerves, vessels and tendons ${ }^{3,5,6}$. Fishing injury related infection although quite common and usually trivial, but sometimes can cause severe sepsis and death ${ }^{2}$. Most of the fishing equipments like hooks or harpoons are designed to catch hold the resisting fish and are therefore usually sharp and narrow in the front and wider in the rear with or without spurs. Because of their very irregular shape, simple extraction by pulling is not recommended, because further damage may occur ${ }^{5}$.

\section{Case Report}

A 17 years old fishermanpresented with penetrating injury of right foot with a harpoon, he reported to emergency ward of Bone and Joint Hospital Srinagar 3 hours after the injury. He presented with pain and swelling right foot and a harpoon with one of its hooks stuck overthe dorsum of right foot. Bleeding from wound was mild. Capillary refill and sensations distal to the wound were normal. Tetanus toxoid and antibiotic prophylaxis was started and patient was prepared for removal of the harpoon under general anaesthesia. Under all aseptic conditions the Protruding part of the harpoon was cut using cutter, hooked end of the Harpoon was advanced forwards. A small incision was given to make way for the barbed end. The hooked part was located and was cut below the barbed end. The remaining portion of the hook was removed from the entry site. Thorough wound cleaning was done with normal saline and antiseptic dressing was applied.

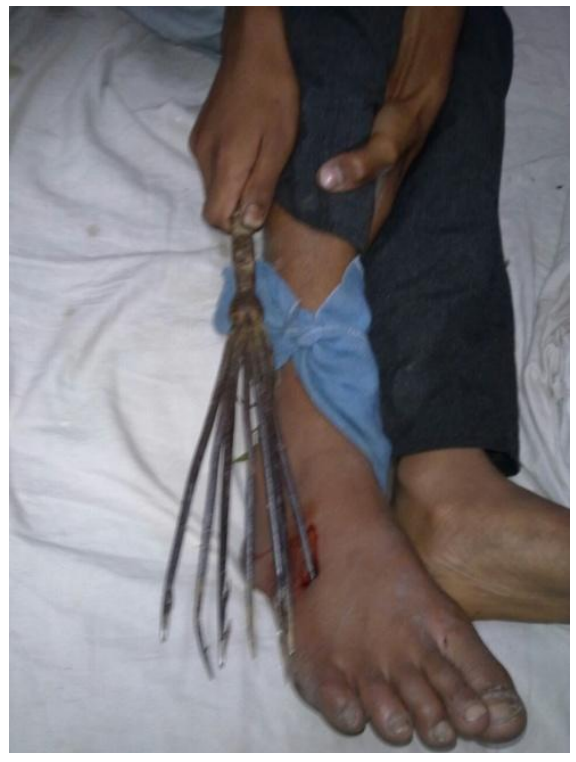

rpo 
17 years old Fisherman with penetrating injury to right foot due to a Harpoon, with one of the hooked end of the Harpoon stuck on the dorsum of the foot.

\section{Discussion}

Fishing involves millions of people throughout the world and is considered as a pleasant and harmless sport ${ }^{4}$. But many type of injuries can occur during fishing. The potential dangers of hooks and harpoons have been highlighted recently ${ }^{6}$. The hand is most commonly injured followed by head and eyes ${ }^{3,5,6}$, injuries involving the lower extremities are rare. Most penetrating objects can be extracted under local anaesthesia in the emergency department. When neural or vascular damage is a possibility or actually present on admission, safe extraction requires general or regional anaesthesia, widening of the penetrating wound, and careful exploration of the object tract to prevent further damage to neurovascular structures ${ }^{5}$. Because the shape of the fishing equipments like hooks and harpoons is not uniform, information on its exact shape and location is of utmost importance before extraction, as most of these objects are metal, simple radiographs are adequate for this purpose ${ }^{4}$.Various techniques are used to remove the hooked fishing harpoons like Retrograde technique, String pull technique, Needle cover technique ${ }^{3}$. The "Push Through and Cut off" technique is used successfully in all types of fishing instruments having barbed ends ${ }^{6}$. A small incision over the anaesthetized skin exposes the barbed tip. The equipment is pushed through and the barbed end is cut under direct vision, thus minimizing injury to soft tissues or underlying structures. The remaining part is backed out via the entry site ${ }^{6}$. Thorough saline washing and proper tetanus prophylaxis are the basic requirements ${ }^{5,6}$. Prophylactic oral fluoroquinolones to cover Aeromonas hydrophila are recommended for deep wounds ${ }^{1}$. Skiendzielewski et al ${ }^{1}$ in one case report of wound infection due to fresh water contamination by Aeromonas hydrophila concluded this pathogen must be suspected in all wounds occurring in fresh water.

\section{Conclusion}

Penetrating injuries due to fishing equipments like harpoons should be managed by an expert after taking proper aseptic precautions to decrease the chances of neurovascular and soft tissue injuries. Hooked ends of the Harpoon should be removed using proper technique preventing neurovascular injury during removal.

\section{References:}

[1]. Skiendzielewski jj, O Keefe KP. Wound infection due to fresh water contamination by Aeromonas hydrophila. J Emerg Med. 1990;8(6):701-3

[2]. Yoshida N, Iwamoto M, Mukae H, et al. A case of fetal sepsis due to vibrio vulnificus. Kansenshogaku Zarshi. 1990; 64: 236-42

[3]. Doser C, Cooper WL, Ediger WM, magen NA, et al Fish hook injuries; a prospective evaluation. Am J Emerg Med. 1991;9(5): 4135

[4]. Lammers RL, Magill T. Detection and management of foreign bodies in soft tissues. Emerg Med Clin North Am 1992;10:767-81

[5]. I Dudkiewicz, M Salai, A Blankstein, et al. Fishing penetration injuries. Br J Sports Med 2000;34: 459-462

[6]. Hayat Ahmad Kan et al. Fish Hook Injury: Removal by "push through and cut off": A case report and brief review of literature. Trauma Mon. 2014 April;19(2):e17728

\footnotetext{
Authors:

1. Omar Khursheed; MBBS, MS Ortho Bone and Joint Hospital Srinagar. E-mail. babaomar53@gmail.com.

2. Ansarul Haq Lone; MBBS, MS Ortho. Bone and Joint Hospital Srinagar. E-mail- imentufail44@gmail.Com.

3. Refut Arah; MBBS, MS. Registrar Postgraduate Department of Surgery Govt. Medical College Srinagar.

4. Azher Maqbool Khan; MBBS, MD, Radiodiagnosis GMC Jammu.

5. Nazeefa. MBBS GMC Srinagar

6. Shazia Altaf. MBBS GMC Srinagar. E-mail. shaziaaltaf13@gmail.com
} 